\title{
A study of morbidity pattern among elderly population in urban India
}

\author{
Akhilesh Yadav, Jang Bahadur Prasad ${ }^{1}$, Chander Shekher ${ }^{1}$, Minakshi Vishvakarma ${ }^{1}$ \\ Department of Community Medicine, Banaras Hindu University, Varanasi, Uttar Pradesh, ${ }^{1}$ Department of Population Studies, \\ International Institute for Population Sciences, Mumbai, Maharashtra, India
}

Abstract

Background: The people in urban area were suffering from different type of morbidities like chronic lung disease, depression, angina, diabetes, etc. Therefore, this study was designed to explore the age pattern of morbidities, level of substance use among elderly, and relationship between substances used and selected morbidities among elderly in urban India.

Material and Methods: The information on morbidity was obtained from Study on Global Ageing and Adult Health (SAGE) - 2007. The methods bivariate and multivariate were used for analyzing the data.

Results and Discussion: The hypertension, depression, diabetes and disease-related to oral health were highly prevalent in the age group of 50-59 years, while cataracts, asthma, and stroke were more frequent in 60-69 years. In urban India, around every second people in the age group of 50-59 years were smokers whereas people were more alcoholic in 60-69 years. In urban India, Assam was the state where the prevalence of smoking was highest while alcohol consumption was highest in the state of Rajasthan and lowest was in Assam. Moreover, among the elderly people; the third most powerful killer disease (diabetes) was highest in the age the group of 50-59 years. Age, tobacco consumption and improvements in wealth quintile were significant risk factors associated with the presence of morbidities like diabetes, hypertension, and stroke. Asthma and oral health were significant increases along with age.

Conclusion: Study confirm that, for reducing these non communicable diseases, there is need to improve old age policy to make proper intension towards the health facility especially among the elderly of middle and higher economic households.

Keywords: Alcohol, elderly, pattern of morbidity, tobacco, urban India

Address for correspondence: Jang Bahadur Prasad, New Hostel, International Institute for Population Sciences, Govandi Station Road, Deonar, Mumbai - 400 008, Maharashtra, India.

E-mail: jbiips12@gmail.com

Received: 22.12.2016, Accepted: 09.03.2017

\section{INTRODUCTION}

Aging is a universal phenomenon associated with deteriorating health status. It is said with the intention of no one grows old merely by living a definite number of years. With the passage of time, particular changes take place in

\begin{tabular}{|l|l|}
\hline \multicolumn{2}{|c|}{ Access this article online } \\
\hline Quick Response Code: & Website: \\
\hline & www.joshd.net \\
\cline { 2 - 2 } & DOI: \\
& 10.4103/joshd.J_Soc_Health_ \\
\hline
\end{tabular}

an organism, leading to morbidities, disabilities, and even death. ${ }^{[1]}$ The boundary of old age cannot be defined because it does not have the same importance in all societies. Indian government adopted "National Policy on Older Persons" in January 1999. The policy defines "senior citizen" or

This is an open access article distributed under the terms of the Creative Commons Attribution-NonCommercial-ShareAlike 3.0 License, which allows others to remix, tweak, and build upon the work non-commercially, as long as the author is credited and the new creations are licensed under the identical terms.

For reprints contact: reprints@medknow.com

How to cite this article: Yadav A, Prasad JB, Shekher C, Vishvakarma M. A study of morbidity pattern among elderly population in urban India. J Soc Health Diabetes 2017;5:100-6. 
"elderly" as a person who is of age 60 years or above. ${ }^{[2]}$ The lessening in fertility level, reinforced by a steady enlarge in the life expectancy has produced primary changes in the age composition of the population, which in turn leads to the aging inhabitants. The needs and troubles of the elderly vary notably according to their age, socioeconomic status, health, living status, and other such background characteristics. ${ }^{[3]}$

In 2010, an estimated 524 million people were aged 65 or older $-8 \%$ of the world's population. This number is probably to almost triple to about 1.5 billion, representing $16 \%$ of the world's people till $2050 .{ }^{[4]}$ In India, the population over the age of 60 years has tripled in the last 50 years and will relentlessly increase in the future. The proportion of older people was $7.7 \%$ in 2001, which will rise to $8.1 \%$ in 2011 and $8.9 \%$ in 2016 (Operational Guidelines, National Programmer for the Health Care of the Elderly, Ministry of Health and Family Welfare Department-Government of India).

Aging of a population is an issue of great concern for the health segment. The elderly as the whole are less healthy than the nonelderly. ${ }^{[5]}$ The health problems are acknowledged to increase with age, and this demographic trend may lead to enhance the absolute number of health conditions in the population. The aged population has unique health problems that are different from those of adults or young. The majority of diseases in aged are chronic in nature such as cardiovascular diseases, arthritis, stroke, diabetes, cataract, deafness, cancer, and chronic infections. Most often, elderly may undergo from the multiple chronic situations, visual defects, hearing impairment, and deterioration of speech which can cause social isolation. In addition, because there is a growing body of evidence that older people are at risk for multiple, comorbid conditions, health-care seeking will probably also increase. ${ }^{[6]}$

The elderly condition differs from one place to another; especially they are entirely different in rural and urban setting. Living conditions vary in the city, and they are vulnerable to various risk factors in the urban environment. There is a limited study on morbidity pattern among the elderly population in urban India based on the Study on Global Ageing and Adult Health (SAGE) data, 2007. Most of the studies focus on the elderly population of the particular area. However, according to the literature, the urban area is also at the risk of a different type of morbidities such as chronic lung disease, depression, and angina. Therefore, this study was taken up with the objective of exploring the age pattern of morbidity, level of substance use among elderly, and relationship between substance uses among the elderly population in urban India to improve our health-care services.

\section{MATERIAL AND METHODS}

\section{Data source}

The data on morbidity were obtained from the SAGE-2007. The International Institute for Population Sciences, Mumbai, was in partnership with the World Health Organization (WHO), Geneva in enterprise the SAGE, 2007 in India. The SAGE was the part of global longitudinal study implement in six countries, namely, China, Ghana, India, Mexico, South Africa, and Russia. In India, it had been conducted in six states (Assam, Maharashtra, Karnataka, Uttar Pradesh, West Bengal, and Rajasthan). The SAGE was covered a sample of 10,600 households across the six states. Moreover, it was followed-up the same primary sampling units, and the sample households covered across the selected states in the World Health Survey in India. It was likely to run for up to 10 years with follow-up effect for each 2 years. The primary purpose of SAGE was to assess the health, well-being, and social determinants of the elderly people age of 50 plus.

\section{Methodology}

The bivariate and multivariate analysis were used to measure the age pattern of morbidity, level of substance use among elderly, and the relationship between substance use and selected morbidity among the elderly population in urban India. In other words, bivariate was used for simple morbidity distribution while multivariate was for estimation of the risk of the level of substance use among elderly, and the relationship between substance use and selected morbidity according to the selected background characteristics.

\section{Binary logistic regression}

The binary logistic regression analysis was applied to obtain the odds of different types of morbidity among the elderly population in urban India. The dependent variable in the model is chronic lung disease, diabetes, depression, cataracts, arthritis, stroke, angina, asthma, and oral health. The maximum likelihood function commonly estimates logistic regression.

Lets Yi is outcome variables, and Xi's are covariates (set of explanatory variables which can be discrete, continuous, or a combination) and $\beta$ i's are coefficients, and then, logistic regression model takes the form:

$P=\operatorname{Prob}(Y i=1 \mid X i=x i)=\frac{\exp (\beta 0+\beta 1 \mathrm{xi})}{1+\exp (\beta 0+\beta 1 \mathrm{xi})}$

\section{OR}


Yadav, et al.: A study of morbidity pattern among elderly population in urban India

$$
\begin{aligned}
\log \operatorname{it}(P) & =\log \left(\frac{P}{I-P}\right) \\
= & \beta 0+\beta 1 \mathrm{X} 1+\beta 2 \mathrm{X} 2+\beta 3 \mathrm{X} 3+\ldots . .+\beta_{\mathrm{n}} \mathrm{Xn}
\end{aligned}
$$

Where $P$ is predicted the probability and $\log$ odd of $P$ and $(1-P)$ provides the odds ratios on the reference category.

\section{RESULTS}

The age pattern of morbidity in urban India is shown in Table 1 which indicates that chronic lung disease was highest $(55.2 \%)$ in the age group of $70-79$ years and lowest $(1.6 \%)$ in the age group of 80 and above years of people. The people suffering from diabetes $(48.4 \%)$, depression (45.6\%), and hypertension (44.8\%) were more in the age group of 50-59 years than the others age groups. A cataract was highly prevalent $(33.2 \%)$ in the age group of 70-79 years and lesser (6.6\%) in 80 and above years. Forty-eight percent people in urban India were suffering from arthritis in the age group of 50-59 years and a stroke was highest $(41.5 \%)$ in the age group of 60-69 years and $36 \%$ were from angina in the age group of 50-59. Asthma was highly prevalent in the age group 60-69 (41.1\%) and least $(3.1 \%)$ in the age group of 80 and above. The disease related to oral health was high (40.6\%) among the people of $50-59$ years and least $(6 \%)$ in the age group of 80 plus years.

Table 2 reveals the percent distribution of substance use in the different age group of the study population. It shows that $34.6 \%$ elderly people were consumed tobacco, in which $37 \%$ people was ever smoked in the age group of 50-59 years. Moreover, $1.8 \%$ people were ever consumed alcohol in the age group of 60-69 followed by 70-79 years of people. The person who consumed both tobacco and alcohol was $18.2 \%$ in the age group of 70-79 years which was highest than the others age group people. Elsewhere, it was lowest $(3.3 \%)$ in the age group of 80 and above years.

Table 3 shows the state-wise distribution of substance use in urban India and according to this; almost $62 \%$ ever smoked was from Assam and followed by the Uttar Pradesh (47.3\%) and West Bengal (41.4\%). Elsewhere, it was less in Maharashtra (22.1\%) state. Rajasthan $(2.8 \%)$ had highest percentage of alcohol consumer followed by Maharashtra (2\%). In urban India, Assam was the state where people were ignoring to consume the alcohol. Moreover, the person who smoked tobacco or consumed alcohol was 18\% in Maharashtra, followed by Rajasthan (7.8\%), West Bengal (7.3\%), Karnataka (5.8\%), Uttar Pradesh (5.5\%), and Assam (2.9\%).
Table 1: Distribution of selected morbidity by age group among urban elderly population in India, 2007

\begin{tabular}{lccccc}
\hline Morbidity & \multicolumn{4}{c}{$\begin{array}{c}\text { Age group of elderly population: } \\
\text { India, 2007 }\end{array}$} \\
\cline { 2 - 5 } & $50-59$ & $60-69$ & $70-79$ & $85+$ & \\
\hline Chronic lung diseases & 27.6 & 15.6 & 55.2 & 1.6 & 63 \\
Diabetes & 48.4 & 25.5 & 24.0 & 2.1 & 166 \\
Depression & 45.6 & 42.2 & 10.3 & 1.8 & 49 \\
Hypertension & 44.8 & 25.4 & 26.7 & 3.2 & 354 \\
Cataracts & 28.3 & 31.9 & 33.2 & 6.6 & 251 \\
Arthritis & 48.4 & 28.0 & 20.4 & 3.2 & 260 \\
Stroke & 27.9 & 41.5 & 30.4 & 0.2 & 37 \\
Angina & 36.5 & 30.1 & 30.8 & 2.5 & 115 \\
Asthma & 33.0 & 41.1 & 22.8 & 3.1 & 117 \\
Oral health & 40.6 & 30.2 & 23.3 & 6.0 & 263 \\
Total & 38.1 & 31.2 & 27.7 & 3.0 & 1676 \\
\hline
\end{tabular}

Table 2: Distribution of substance use in different age group, urban India, 2007

\begin{tabular}{lccccc}
\hline Age group & \multicolumn{5}{c}{ Substance use } \\
\cline { 2 - 6 } & Alcohol & Alcohol and tobacco & Tobacco & None & $n$ \\
\hline $50-59$ & 1.80 & 6.80 & 37.00 & 54.50 & 760 \\
$60-69$ & 1.80 & 11.10 & 33.90 & 53.20 & 552 \\
$70-79$ & 0.20 & 18.20 & 29.80 & 51.80 & 293 \\
$80+$ & 0.10 & 3.30 & 34.50 & 62.40 & 71 \\
Total & 1.40 & 10.10 & 34.60 & 53.90 & 1676 \\
\hline
\end{tabular}

Table 3: Distribution of substance use in different state, urban India, 2007

\begin{tabular}{lccccc}
\hline States & \multicolumn{5}{c}{ Substance use } \\
\cline { 2 - 6 } & Alcohol & Alcohol and tobacco & Tobacco & None & $n$ \\
\hline Assam & 0 & 2.9 & 61.9 & 35.3 & 127 \\
Karnataka & 0.8 & 5.8 & 28.7 & 64.7 & 299 \\
Maharashtra & 2.0 & 18.0 & 22.1 & 57.9 & 467 \\
Rajasthan & 2.8 & 7.8 & 36.4 & 53.0 & 261 \\
Uttar Pradesh & 1.0 & 5.5 & 47.3 & 46.2 & 199 \\
West Bengal & 1.1 & 7.3 & 41.4 & 50.3 & 323 \\
Total & 1.4 & 10.1 & 34.6 & 53.9 & 1676 \\
\hline
\end{tabular}

Table 4 indicates the association of diabetes, depression, and hypertension along with selected background characteristics. The odd of having diabetes was 2.1 times more in the age group of 60-69 years as compared to the age group of 50-59 years. The people who were exposed to alcohol had 1.9 times more risk of diabetes as compared to nonexposed to alcohol. The people who had 10 plus years of education were 2.41 times more risk of diabetes than the illiterate people, i.e., the highly educated people had high chance of getting diabetes. A person belongs to other caste (except schedule caste $[\mathrm{SC}]$ and schedule tribe $[\mathrm{ST}]$ ) had 2.1 times higher risk of diabetes than SCs/STs.

The odds of having diabetes were 2.5, 2.5, and 2.7 times more among the individual belong to the middle, richer, and richest wealth quintile than person belongs to poor wealth quintile. A person who was exposed to tobacco had $80 \%$ greater risk of depression as compared to nonexposed. However, the odds of having hypertension 
Table 4: Results of logistic regression of diseases, diabetes, depression, and hypertension with socioeconomic and background characteristics, urban India, 2007

\begin{tabular}{|c|c|c|c|c|c|c|c|c|c|}
\hline \multirow[t]{2}{*}{ Background characteristics } & \multicolumn{3}{|c|}{ Diabetes } & \multicolumn{3}{|c|}{ Depression } & \multicolumn{3}{|c|}{ Hypertension } \\
\hline & $\operatorname{Exp}(B)$ & Lower & Upper & $\operatorname{Exp}(B)$ & Lower & Upper & $\operatorname{Exp}(B)$ & Lower & Upper \\
\hline \multicolumn{10}{|l|}{ Age group } \\
\hline \multicolumn{10}{|l|}{$50-59$ ** } \\
\hline $60-69$ & 1.34 & 0.97 & 1.87 & 1.37 & 0.76 & 2.46 & $1.58^{*}$ & 1.22 & 2.05 \\
\hline $70-79$ & $2.09^{*}$ & 1.44 & 3.03 & 0.62 & 0.25 & 1.54 & $2.27^{\star}$ & 1.68 & 3.07 \\
\hline $80+$ & 1.29 & 0.61 & 2.73 & 1.61 & 0.53 & 4.92 & $1.91^{\star}$ & 1.12 & 3.27 \\
\hline \multicolumn{10}{|l|}{ Alcohol consumption } \\
\hline \multicolumn{10}{|l|}{$\mathrm{No}^{* *}$} \\
\hline Yes & $1.90^{\star}$ & 1.26 & 2.88 & 1.07 & 0.47 & 2.43 & 1.01 & 0.70 & 1.46 \\
\hline \multicolumn{10}{|l|}{ Tobacco consumption } \\
\hline \multicolumn{10}{|l|}{$\mathrm{No}^{* *}$} \\
\hline Yes & $1.79^{*}$ & 1.58 & 1.83 & $1.77^{\star}$ & 1.01 & 3.10 & $1.90^{*}$ & 1.71 & 1.97 \\
\hline \multicolumn{10}{|l|}{ Education level } \\
\hline \multicolumn{10}{|l|}{ No education** } \\
\hline Less than high school & $1.72^{*}$ & 1.17 & 2.53 & 0.57 & 0.32 & 1.05 & 0.78 & 0.60 & 1.03 \\
\hline Greater than or equal to high school & $2.41^{\star}$ & 1.57 & 3.69 & 0.42 & 0.18 & 0.96 & 0.94 & 0.69 & 1.30 \\
\hline \multicolumn{10}{|l|}{ Religion } \\
\hline \multicolumn{10}{|l|}{ Others** } \\
\hline Hindu & 0.86 & 0.58 & 1.28 & 1.42 & 0.65 & 3.08 & 1.11 & 0.81 & 1.51 \\
\hline \multicolumn{10}{|l|}{ Caste } \\
\hline \multicolumn{10}{|l|}{$\mathrm{SC} / \mathrm{ST}^{* *}$} \\
\hline Others & $2.14^{*}$ & 1.22 & 3.73 & 2.06 & 0.80 & 5.31 & $1.78^{*}$ & 1.21 & 2.62 \\
\hline \multicolumn{10}{|l|}{ Wealth index } \\
\hline \multicolumn{10}{|l|}{ Poor** } \\
\hline Middle & $2.46^{*}$ & 1.33 & 4.55 & 1.14 & 0.48 & 2.72 & $2.19^{*}$ & 1.43 & 3.35 \\
\hline Rich & $2.48^{*}$ & 1.37 & 4.50 & 2.05 & 0.94 & 4.46 & $2.55^{\star}$ & 1.70 & 3.83 \\
\hline Richest & $2.65^{\star}$ & 1.47 & 4.78 & 0.74 & 0.29 & 1.86 & $2.88^{\star}$ & 1.92 & 4.31 \\
\hline
\end{tabular}

${ }^{*} P<0.05,{ }^{*}$ Reference. Poor: Poorest + poorer. SC: Schedule caste, ST: Schedule tribe

Table 5: Results of logistic regression of diseases, asthma, chronic lung disease, and oral health with socioeconomic and background characteristics, urban India, 2007

\begin{tabular}{|c|c|c|c|c|c|c|c|c|c|}
\hline \multirow[t]{2}{*}{ Background characteristics } & \multicolumn{3}{|c|}{ Asthma } & \multicolumn{3}{|c|}{ Chronic lung disease } & \multicolumn{3}{|c|}{ Oral health } \\
\hline & $\operatorname{Exp}(B)$ & Lower & Upper & $\operatorname{Exp}(B)$ & Lower & Upper & $\operatorname{Exp}(B)$ & Lower & Upper \\
\hline \multicolumn{10}{|l|}{ Age group (years) } \\
\hline \multicolumn{10}{|l|}{$50-59 * *$} \\
\hline $60-69$ & $1.73^{*}$ & 1.10 & 2.70 & 1.53 & 0.77 & 3.04 & 1.22 & 0.89 & 1.65 \\
\hline 70-79 & $1.85^{\star}$ & 1.09 & 3.12 & $2.71^{\star}$ & 1.33 & 5.52 & $1.66^{*}$ & 1.17 & 2.36 \\
\hline $80+$ & $2.49^{*}$ & 1.10 & 5.63 & 2.14 & 0.60 & 7.69 & $3.21^{\star}$ & 1.87 & 5.48 \\
\hline \multicolumn{10}{|l|}{ Alcohol consumption } \\
\hline \multicolumn{10}{|l|}{$\mathrm{No}^{* *}$} \\
\hline Yes & 1.60 & 0.93 & 2.74 & $2.26^{*}$ & 1.15 & 4.47 & 0.96 & 0.62 & 1.47 \\
\hline \multicolumn{10}{|l|}{ Tobacco consumption } \\
\hline \multicolumn{10}{|l|}{$\mathrm{No}^{* *}$} \\
\hline Yes & 1.10 & 0.73 & 1.65 & $2.03^{*}$ & 1.10 & 3.73 & 1.07 & 0.81 & 1.41 \\
\hline \multicolumn{10}{|l|}{ Education level } \\
\hline \multicolumn{10}{|l|}{ No education** } \\
\hline Less than high school & 1.61 & 1.01 & 2.54 & 1.08 & 0.56 & 2.09 & 0.75 & 0.55 & 1.02 \\
\hline Greater than or equal to high school & 0.93 & 0.50 & 1.71 & 0.87 & 0.37 & 2.04 & 0.79 & 0.54 & 1.16 \\
\hline \multicolumn{10}{|l|}{ Religion } \\
\hline \multicolumn{10}{|l|}{ Others ${ }^{\star *}$} \\
\hline Hindu & 1.35 & 0.76 & 2.38 & 0.83 & 0.40 & 1.71 & 0.85 & 0.60 & 1.20 \\
\hline \multicolumn{10}{|l|}{ Caste } \\
\hline \multicolumn{10}{|l|}{$\mathrm{SC} / \mathrm{ST}^{* *}$} \\
\hline Others & 1.27 & 0.70 & 2.30 & 1.53 & 0.63 & 3.71 & 1.12 & 0.75 & 1.66 \\
\hline \multirow{2}{*}{\multicolumn{10}{|c|}{$\begin{array}{l}\text { Wealth index } \\
\text { Poor**}\end{array}$}} \\
\hline & & & & & & & & & \\
\hline Middle & 0.76 & 0.42 & 1.38 & 0.40 & 0.16 & 1.00 & 0.61 & 0.40 & 0.93 \\
\hline Rich & 0.80 & 0.46 & 1.41 & 0.58 & 0.26 & 1.27 & 0.74 & 0.50 & 1.10 \\
\hline Richest & 0.69 & 0.39 & 1.24 & 0.71 & 0.33 & 1.55 & 0.75 & 0.51 & 1.11 \\
\hline
\end{tabular}

$* P<0.05, * *$ Reference. Poor: Poorest+poorer. SC: Schedule caste, ST: Schedule tribe

was 1.6, 2.3, and 1.9 times more in the age group 60-69, $70-79$, and $80+$, respectively than the age group of
50-59 years. A person belongs to other caste were 1.8 times more likely to had hypertension as compared 
to SCs/STs. Moreover, the odds of having hypertension were 2.2, 2.6, and 2.9 times more among the people belong to middle, richer, and richest wealth quintile than person belongs to poor wealth quintile.

Table 5 shows the association of asthma, chronic lung disease, and illness related to oral health along with different selected background characteristics. The odd of having hypertension was $1.7,1.9$, and 2.5 times more in the age group of $60-69,70-79$, and $80+$ years, respectively, as compared to the age group of 50-59 years. Elsewhere, the odds of having the chronic lung disease were 2.7 times higher in the age group of 70-79 years than the age group 50-59 years. A person who was exposed to alcohol had 2.3 times greater risk of chronic lung disease. Elsewhere, the person who was exposed to tobacco had also 2.03 times greater chance of having chronic lung disease than the nonexposed. Moreover, the odds of having a disease related to oral health were 1.7 and 3.2 times more in the age group of 70-79 and 80+ years, respectively, as compared to the age group 50-59 years.

Although Table 6 shows the association of stroke and arthritis according to selected background characteristics. The odds of having a stroke were 3.1 and 3.9 times more in the age group 60-69 and 70-79 years, respectively, than the age group 50-59 years. A person who was exposed to tobacco had 1.9 times higher risk of stroke as compared to nonexposed. The odds of having stroke were 6.1 and 6.2 times greater chance among the individual belong to middle and richest wealth quintile than the person belongs to poor wealth quintile. Moreover, the odds of having arthritis were 1.3 and 1.5 times more in the age group of 60-69 and 70-79 years than the age group of 50-59 years. A person belongs to other caste had 1.7 times more likely to risk of arthritis as compared to SCs/STs.

\section{DISCUSSION}

Tobacco consumption was highest in Assam because Assam was a state who manufactures a large amount of smoking and smokeless tobacco in every year. Past recorded history shows it was used not only for therapeutic effect but also for recreation purposes to enhance the pleasure and relative stress $^{[7]}$ but as time was passed, it came into habit. Elsewhere, tobacco consumption was also a fashion. Moreover, this study also indicates highest morbidity (38.1\%) is in the age group of 50-59 years while a study carried out in the southern part of India reported that the prevalence of morbidity is highest $(82.9 \%)$ in the age group of 60 years and above. ${ }^{[8]} \mathrm{A}$ high prevalence of Arthritis is in the age group of 50-59 years while after this age group, it was declined. It might be because of life expectancy. Moreover, India's life expectancy is 66.5

Table 6: Results of logistic regression of diseases stroke and arthritis with socioeconomic and background characteristics, urban India, 2007

\begin{tabular}{|c|c|c|c|c|c|c|}
\hline \multirow[t]{2}{*}{ Background characteristics } & \multicolumn{3}{|c|}{ Stroke } & \multicolumn{3}{|c|}{ Arthritis } \\
\hline & $\operatorname{Exp}(B)$ & Lower & Upper & $\operatorname{Exp}(B)$ & Lower & Upper \\
\hline \multicolumn{7}{|l|}{ Age group (years) } \\
\hline \multicolumn{7}{|l|}{$50-59 * \star$} \\
\hline $60-69$ & $3.11^{\star}$ & 1.45 & 6.66 & $1.34^{\star}$ & 1.01 & 1.79 \\
\hline $70-79$ & $3.93^{*}$ & 1.73 & 8.94 & $1.50^{*}$ & 1.07 & 2.11 \\
\hline 80 and above & 1.09 & 0.14 & 8.78 & 1.30 & 0.71 & 2.40 \\
\hline \multicolumn{7}{|l|}{ Alcohol consumption } \\
\hline \multicolumn{7}{|l|}{$\mathrm{No}^{* *}$} \\
\hline Yes & 0.80 & 0.32 & 2.02 & 1.06 & 0.70 & 1.60 \\
\hline \multicolumn{7}{|l|}{ Tobacco consumption } \\
\hline Yes & $1.87^{\star}$ & 1.02 & 3.44 & 0.81 & 0.61 & 1.06 \\
\hline \multicolumn{7}{|l|}{ Education level } \\
\hline \multicolumn{7}{|l|}{ No education** } \\
\hline Less than high school & 0.69 & 0.33 & 1.43 & 0.85 & 0.63 & 1.14 \\
\hline Greater than or equal to high school & 1.07 & 0.48 & 2.37 & 0.70 & 0.49 & 1.02 \\
\hline \multicolumn{7}{|l|}{ Religion } \\
\hline \multicolumn{7}{|l|}{ Others** } \\
\hline Hindu & 0.93 & 0.42 & 2.08 & 1.17 & 0.82 & 1.65 \\
\hline \multicolumn{7}{|l|}{ Caste } \\
\hline \multicolumn{7}{|l|}{$\mathrm{SC} / \mathrm{ST}^{\star \star}$} \\
\hline Others & 0.95 & 0.39 & 2.33 & $1.73^{\star}$ & 1.13 & 2.65 \\
\hline \multicolumn{7}{|l|}{ Wealth index } \\
\hline \multicolumn{7}{|l|}{ Poor** } \\
\hline Middle & $6.07^{\star}$ & 1.33 & 27.63 & 1.24 & 0.82 & 1.88 \\
\hline Rich & 4.08 & 0.87 & 19.01 & 1.35 & 0.90 & 2.01 \\
\hline Richest & $6.21^{*}$ & 1.38 & 27.94 & 1.06 & 0.71 & 1.59 \\
\hline
\end{tabular}


as from the 2015 revision of world population prospects. Some study reported that this problem is high, especially among female, possibly reflecting hard life like spending more time at home. ${ }^{[9-11]}$ The women who never retired from household work unless completely disable.

In urban India, approximately, every second person was suffering from morbidities such as hypertension, depression, and diabetes in the age group of 50-59 years. The prevalence was also highest among elderly suffering from hypertension in the reported WHO report. ${ }^{[12]}$ The studies conducted in Chandigarh considered a person will be hypertensive if blood pressure is to be higher than $140 / 90 \mathrm{~mm}$ of mercury as per the criteria of the WHO. ${ }^{[10,13]}$ The presence of hypertension may be because of modern life and stress in urban settings. This study is also showing more in other castes (other than SCs/STs) as compared to SCs/STs. Moreover, it was high in the middle, rich, and richest households than the poor households. The people having hypertension had more chance of Angina disease. Moreover, there is a significant relationship between hypertension and smoking. A study reported that nicotine may cause in rising systolic and diastolic blood pressure, ${ }^{[14]}$ while another study reported that there is a need to follow the use of smokeless tobacco or tobacco chewers while more prolonged elevations in the blood pressure. ${ }^{[15]}$

Alhough the study indicates that alcohol consumer is more in highly educated and other castes (except non-SCs/STs). The middle and higher economic household's peoples are significantly associated with diabetes. This study also indicates that tobacco consumption was having a significant association with diabetes. Moreover, one of the studies shows that smoking increases the risk of Type 2 diabetes in both male and female. ${ }^{[16]}$ Use of tobacco can increase the level of blood sugar ${ }^{[17]}$ and enhance the insulin resistance. ${ }^{[18]}$ However, some others study shows diabetes is poorly controlled or untreated. Elsewhere, tobacco cuts the amount of oxygen reaching into the body and enhances the level of cholesterol in the blood. ${ }^{[19,20]}$ It is serious problems involve kidney, heart, eyes, and other organs. ${ }^{[21]}$ Since a metabolite of nicotine is positively related to insulin resistance which indicates that nicotine can play a role in the development of diabetes. ${ }^{[2]}$ Another study represents that the people having more than 25 cigarettes per day have nearly 2 times of risk of developing diabetes than nonsmokers. ${ }^{[23]}$ Moreover, the people having diabetes are at increased the risk of stroke and heart attack.

The chronic lung disease was high $(55.2 \%)$ in the age of 70-79 years while it was too much low in below and above age of the people. It is quite interested that the people in the age group of 70-79 years were more alcoholic and tobacco consuming followed by 60-69 years people. One more interested thing is that in urban India after the age of 50 years, alcohol consumption was very less than the consumption of tobacco. Elsewhere, chronic lung disease was significantly more among the people who were consuming alcohol and tobacco. The previous study supported that involuntary smoking linked with increase the risk of lung cancer. ${ }^{[2,25]}$ Asthma and oral health were significantly increased along with age. Moreover, stroke was significantly high among the people in the age group 60-80. It was significantly high among the people living in middle and richest households.

\section{CONCLUSION}

Hypertension, depression, diabetes, and disease-related to oral health were highly prevalent in the age group of 50 59 years. However, asthma and stroke were more frequent in the age group 60-69, and chronic lung disease was more in the age group of 70-79 years. A higher percentage of substance use (alcohol) was in the age group of 60-69 years while tobacco consumers and alcohol drink were elevated in the age group of 70-79 years. Moreover, Assam had a higher percentage of substance use (tobacco) while alcohol consumption was highest in Rajasthan and lowest in Assam. Increasing age, tobacco, and improvement in the household's economics had been created the significant risk factors associated with the presence of diabetes, depression, hypertension, and stroke. Elsewhere, diabetes had a significant association with tobacco consumption. Asthma and oral health were significantly increased along with age. Stroke was significantly high among the people in the age group 60-80. It was significantly high among the people living in the middle and richest households. Hence, for reducing these noncommunicable diseases, there is needed to make proper intention toward the old age policy for facilitated a health facility, especially among the elderly of middle and higher economic households.

\section{Financial support and sponsorship}

Nil.

\section{Conflicts of interest}

There are no conflicts of interest.

\section{REFERENCES}

1. Kishore S, Juyal R, Semwal J, Chandra R. Morbidity profile of elderly persons. Eye 2007;36:30-45.

2. Shraddha K, Prashantha B, Prakash B. Study on morbidity pattern among elderly in Urban population of Mysore, Karnataka, India. Int J Med Biomed Res 2013;1:215-23.

3. Ramakrishna Reddy N, Kishore SG, Riyaz Basha S. Morbidity 
pattern among elderly population in the old age homes of Bangalore, Karnataka, India. Indian J Rural Health 2014;2:1147-319.

4. WHO, National Institutes of Health. Global Health and Aging. Publication No. 11-7737. U.S: WHO, National Institutes of Health; 2011. p. 4.

5. Karim HA. The elderly in Malaysia: Demographic trends. Med J Malaysia 1997;52:206-12.

6. Kumari R. Socio-economic conditions, morbidity pattern and social support among the elderly women in a rural area. Sreekarym-Panchayat, India; 2001. p. 1-78.

7. Ramakrishna GS, Sankara Sarma P, Thankappan KR. Tobacco use among medical students in Orissa. Natl Med J India 2005;18:285-9.

8. Niranjan GV, Vasundhra MK. A study of health status of aged persons in slums of Urban field practice area, Bangalore. Indian J Community Med 1996;21:37-40.

9. Niranjan GV, Vasundhra MK. A study of health status of aged persons in slums of Urban field practice area, Bangalore. Indian J Community Med 1996;21:1-4.

10. Sharma OP, Pandey JN, Manchanda SC. Geriatric Care in India: Geriatrics and Gerontology. A Text Book. New Delhi: ANB Publishers Pvt. Ltd. 1999. p. 8-13.

11. Purty AJ, Bazroy J, Kar M, Vasudevan K, Zacharia P, Panda P. Morbidity pattern among the elderly population in the rural area of Tamil Nadu, India. Turk J Med Sci 2006;36:45-50.

12. World Health Organization. Epidemiology and Prevention of Cardiovascular Diseases in Elderly People: Report of a WHO Study Group. Genewa: World Health Organization; 1995.

13. Swami HM, Bhatia V, Dutt R, Bhatia SP. A community based study of the morbidity profile among the elderly in Chandigarh, India. Bahrain Med Bull 2002;24:16-20.

14. Groppelli A, Giorgi DM, Omboni S, Parati G, Mancia G. Persistent blood pressure increase induced by heavy smoking. J Hypertens 1992;10:495-9.

15. Hirsch JM, Hedner J, Wernstedt L, Lundberg J, Hedner T. Hemodynamic effects of the use of oral snuff. Clin Pharmacol Ther 1992;52:394-401.

16. Willi C, Bodenmann P, Ghali WA, Faris PD, Cornuz J. Active smoking and the risk of type 2 diabetes: A systematic review and meta-analysis. JAMA 2007;298:2654-64.

17. Janzon L, Berntorp K, Hanson M, Lindell SE, Trell E. Glucose tolerance and smoking: A population study of oral and intravenous glucose tolerance tests in middle-aged men. Diabetologia 1983;25:86-8.

18. Facchini FS, Hollenbeck CB, Jeppesen J, Chen YD, Reaven GM. Insulin resistance and cigarette smoking. Lancet 1992;339:1128-30.

19. American Diabetes Association. Diabetes. Vol. 15. Arlington: American Diabetes Association; 1966. p. 7-12.

20. Rosenheim KP, Crofton JW, Hunt JH, Dunwoody JEO, Fletcher CM, Harding WG, et al. Action on Smoking and Health. British Medical Journal 1971;1:171.

21. Zainul Z. Dark nights behind the white clouds risks of tobacco smoking on human health besides the oral health and malignancy. EXCLI J 2011;10:69-84.

22. Eliasson B, Taskinen M, Smith U. Long-term use of nicotine gum is associated with hyper insulinemia and insulin resistance. ACC Current J Rev 1997;6:88.

23. Rimm EB, Chan J, Stampfer MJ, Colditz GA, Willett WC. Prospective study of cigarette smoking, alcohol use, and the risk of diabetes in men. BMJ 1995;310:555-9.

24. Hackshaw AK, Law MR, Wald NJ. The accumulated evidence on lung cancer and environmental tobacco smoke. BMJ 1997;315:980-8.

25. Vineis P, Alavanja M, Buffler P, Fontham E, Franceschi S, Gao YT, et al. Tobacco and cancer: Recent epidemiological evidence. J Natl Cancer Inst 2004;96:99-106. 